\title{
The Strategies for the Prevention of Chronic GVHD in Hematopoietic Stem Cell Transplantation
}

\author{
Jong-Wook Lee, M.D., Ph.D. \\ Division of Hematology, Department of Internal Medicine, Catholic Hematopoietic Stem Cell Transplantation Center, \\ College of Medicine, The Catholic University of Korea, Seoul, Korea
}

\begin{abstract}
Chronic graft-versus-host disease (GVHD) is the most frequent late complication after hematopoietic cell transplantation and has a major impact on the quality of life and survival. As the pathophysiology of GVHD is still incompletely understood, it has been difficult to design effective prophylactic regimens. However, prevention of acute GVHD appears to result in a lower incidence of chronic GVHD. The use of younger, non-allo-sensitized donors, preferentially of the same sex as the patient, and the use of stem cells other than G-CSF-mobilized peripheral blood stem cells, are associated with a decreased frequency of chronic GVHD. Further, the incorporation of thymoglobulin into the conditioning regimen has been demonstrated as beneficial to reduce chronic GVHD and delayed complications. (Korean J Hematol 2008;43:1-8.)
\end{abstract}

Key Words: Chronic GVHD, Prevention, Hematopoietic cell transplantation

\section{INTRODUCTION}

Hematopoietic cell transplantation (HCT) provides curative therapy for various diseases. Current data show, indeed, that patients transplanted for aplastic anemia and patients without chronic GVHD have life expectancies similar to age-matched controls. ${ }^{1,2)}$ However, GVHD has remained a frequent complication. With the increase in numbers of transplants over the past three decades and considerable improvement in early post- transplant survival, a growing population of survivors is at risk of developing late complications including chronic GVHD.

An early acute form of GVHD and a delayed chronic form have been described. ${ }^{3)}$ However, a clear distinction between acute and chronic GVHD is no longer tenable. Observations in patients transplanted with reduced-in-

접수 : 2008년 3월 24일, 수정 : 2008년 3월 25일

승인 : 2008년 3월 27일

교신저자 : 이종욱, 서울시 영등포구 여의도동 62번지

(ㅇ) 150-713, 가톨릭대학교 의과대학 성모병원 혈액내과

Tel: 02-3779-1037, Fax: 02-780-3132

E-mail: jwlee@catholic.ac.kr tensity conditioning (RIC) regimens or in patients receiving donor lymphocyte infusions (DLI) at various time intervals after HCT indicate that patients may have acute GVHD several months after transplantation. ${ }^{4)}$ Conversely, GVHD with characteristics of the "chronic" form can occur as early as 2 months after transplantation. ${ }^{4,5)}$ The recent NIH Consensus Conference suggested to distinguish two categories of GVHD: 1) acute GVHD (absence of features consistent with chronic GVHD) comprising a) classic acute GVHD (before day 100), and b) persistent, recurrent or late acute GVHD (after day 100, often upon withdrawal of immunosuppression); and 2) chronic GVHD comprising a) classic chronic GVHD (no signs of acute GVHD), and b) an overlap syndrome, in which features of both acute and chronic GVHD are present. ${ }^{6)}$

GVHD can also occur following administration of

Correspondence to : Jong-Wook Lee, M.D., Ph.D.

Division of Hematology, Department of Internal Medicine, St. Mary's Hospital, College of Medicine, The Catholic University of Korea 62, Yeouido-dong, Yeoungdeungpo-gu, Seoul 150-713, Korea Tel: +82-2-3779-1037, Fax: +82-2-780-3132

E-mail: jwlee@catholic.ac.kr 
blood transfusions (transfusion-associated GVHD) or, under certain circumstances, in patients receiving autologous or syngeneic transplants.

\section{RISK FACTORS AND INCIDENCE}

The most significant risk factor for chronic GVHD is the development of acute GVHD. Early studies showed that about $25 \%$ of patients without preceding evidence of acute GVHD develop "de novo" chronic GVHD, compared to $60 \%$ of those with grade I, and $80 \%$ of those with grades II-IV acute GVHD. ${ }^{8)}$ Thus, in principle, any successful approach to the prevention of acute GVHD should also reduce the frequency of chronic GVHD. Risk factors for the development of acute GVHD, in turn, include histoincompatibility (HLA and "minor" non-HLA antigens) between donor and recipient, increasing patient and donor age, and the intensity of the conditioning regimen used to prepare patients for HCT. The use of G-CSF-mobilized peripheral blood stem cells (PBSC) rather than marrow as a source of donor stem cells has been associated with an increased incidence of acute GVHD in some studies and has consistently resulted in more chronic GVHD. ${ }^{9)}$ Of note, however, this increased incidence of chronic GVHD did not appear to be reflected in decreased survival in patients transplanted from HLA-identical siblings and might have had a beneficial effect on the prevention of disease recurrence in patients at high risk for relapse. ${ }^{9)}$

The $\mathrm{CD} 34^{+}$cell dose in PBSC grafts may affect the development of extensive chronic GVHD after HLAidentical sibling transplantation. ${ }^{10)}$ The use of umbilical cord blood appears to be associated with low rates of chronic GVHD. ${ }^{11)}$

In one study among recipients who survived at least 150 days after HLA-identical marrow transplant the probability of chronic GVHD was $13 \%$ in children less than 10 years old, $28 \%$ in adolescents $10 \sim 19$ years old, and $42 \sim 46 \%$ in adults over age 20 years. $^{12)}$

Among ethnically more homogeneous populations, presumably sharing minor histocompatibility antigens (mHAs), lower rates of chronic GVHD have been reported. ${ }^{13)}$ IBMTR study showed that Americans were at significantly higher risk for acute and chronic GVHD compared to Japanese among pediatric patients who received HLA-identical sibling marrow transplant (relative risk $1.93 ; P=0.04$ and $3.16 ; P=0.002$, for acute and chronic GVHD, respectively). ${ }^{14)}$ An increased risk of chronic GVHD is also associated with grafts from female donors for male recipients, particularly if the donor was alloimmunized by pregnancy or, less frequently, prior transfusions. ${ }^{15)}$ The best explanation for this clinical observation is that mHAs encoded on the Y chromosome can elicit responses from female donors against male recipients. ${ }^{16)}$

Further, some reports suggest that certain HLA antigens are associated with an increased incidence of chronic GVHD in a given ethnic group, for example HLA-DR4 in European patients and HLA-B54 in Koreans. $^{17-19)}$

There have been conflicting reports regarding the relationship between hematopoietic growth factor use (G-CSF and GM-CSF) after HCT and the development of GVHD. A meta-analysis of 18 studies including 1,198 patients failed to reveal differences in the incidence of acute or chronic GVHD in patients who did or did not receive hematopoietic growth factors. ${ }^{20)}$

\section{PATHOPHYSIOLOGY}

The pathophysiology of chronic GVHD is incompletely understood, making it difficult to devise interventional strategies that would be based on disease mechanisms. It is, therefore, not surprising that only few studies have been reported that were aimed specifically at the prevention of chronic GVHD.

Murine chronic GVHD can be induced by transplantation across class I, class II, or minor histocompatibility barriers using irradiation-based regimens or parent into F1 haploidentical combinations without conditioning. In mice, chronic GVHD manifestations are highly dependent on the age of the mice, the strain combinations selected, the number and type of donor cells injected, and the preparative regimen. It has been difficult, however, to extrapolate the murine studies to humans.

Conditioning in preparation for transplantation leads to thymic damage, which in turn may interfere with the 
elimination of self-reactive $\mathrm{T}$ lymphocytes and prevent the development of tolerance. Earlier studies in rodent models suggested that this effect was amplified by the administration of calcineurin inhibitors such as cyclosporine (CSP). ${ }^{21)}$ More recent data from murine mod$\mathrm{els}^{22)}$ indicate specifically that $\mathrm{T}$ cells escaping from thymic selection are involved in the development of chronic GVHD. Studies by Zhang et al. ${ }^{23)}$ show that $\mathrm{CD} 25^{-} \mathrm{CD} 4^{+} \mathrm{T}$ and $\mathrm{B}$ cells are required for chronic GVHD to develop, whereas the presence of $\mathrm{CD} 25^{+} \mathrm{CD} 4^{+}$ (regulatory) $\mathrm{T}$ cells prevented the disease induction. While IL-12 may enhance chronic GVHD development, IL-18 may interfere. ${ }^{24)}$ The role of IL-7 has been somewhat controversial. Initial studies ${ }^{25,26)}$ suggested that IL-7 had a role in promoting peripheral T-cell reconstitution and did not aggravate GVHD. However, work by Sinha et al. ${ }^{27)}$ indicates that $\mathrm{IL}-7$ may aggravate GVHD, and Chung et al. showed that IL-7 was required to induce GVHD in a murine model. ${ }^{28)}$

Clinical studies have shown decreased levels of TREC cells in chronic GVHD, consistent with diminished generation of $\mathrm{T}$ cells by the thymus. ${ }^{29)}$ Current studies are investigating whether an artificial thymus may overcome or bypass thymic atrophy and dysfunction. ${ }^{30)}$ Thymic dysfunction is compounded by the absence of peripheral tolerance mechanisms (e.g. regulatory $\mathrm{T}$ cells). Autoreactive $\mathrm{T}$ lymphocytes appear to be important effector cells leading to interferon gamma-mediated increase in collagen deposition and fibrosis, a characteristic feature of chronic GVHD. ${ }^{31}$

\section{PREVENTIVE STRATEGIES}

As discussed above, clinical studies have identified numerous recipient, donor, and transplant related factors that are associated with higher rates of chronic GVHD. Many of these factors, including older age, diagnosis (e.g., chronic myeloid leukemia, aplastic anemia), and lack of HLA-matched donors cannot be modified. Other factors are modifiable. Assuming availability of multiple HLA-matched donors, selection of a younger related male donor, use of bone marrow rather than peripheral blood, and, possibly, limitation of $\mathrm{CD}^{+} 4^{+}$and $\mathrm{T}$-cell doses infused may reduce the risk of chronic GVHD.
Attention has recently focused on the role of recipient and donor antigen presenting cells (APCs) in attempts to prevent acute GVHD while preserving graft-versus-tumor effects. In patients with myeloid malignancies undergoing haplotype-mismatched and killer immunoglobulin-like receptor (KIR) mismatched transplantation, decreased rates of acute GVHD, decreased relapse rates, and higher overall survival rates have been reported. Chronic GVHD rates were generally not included in those reports. The proposed mechanism of action is elimination of host APCs (decreasing acute GVHD) and host tumor cells (decreasing relapse rates) by uninhibited donor natural killer (NK) cells. ${ }^{32)}$ Another approach to depletion of host APCs has been extracorporeal photopheresis $(\mathrm{ECP})$ in the patient prior to infusion of donor stem cells. In a small series, Chan et al. $^{33)}$ reported lower rates of extensive chronic GVHD, especially when donor dendritic cell (DC) chimerism was achieved by day 100 .

Chao and colleagues conducted a prospective, double-blind study in which 59 patients were randomized to receive, starting on day 80 after HCT, either placebo or thalidomide $(2 \times 200 \mathrm{mg} /$ day $)$, which had been used therapeutically for chronic GVHD, with the aim of preventing chronic GVHD. ${ }^{34)}$ A first interim analysis (based on intent to treat) showed a significant difference in the incidence of GVHD. Paradoxically, however, the incidence of chronic GVHD was higher $(P=0.06)$ and overall survival lower $(P=0.006)$ among thalidomide treated patients, suggesting to the authors that thalidomide had interfered with the establishment of tolerance. These data were reminiscent of earlier experiments in rodent models, which provided evidence that CSP could interfere with tolerance development via injury of the thymic stroma. $^{21)}$

There was also considerable interest in the use of intravenous immunoglobulin (IVIG) for the prevention of infections as well as GVHD in patients after HCT. However, only one randomized study suggested a benefit for the prevention of acute GVHD, and none showed any significant impact on the incidence of chronic GVHD. $^{35)}$

Seattle group randomized patients transplanted from HLA-identical siblings, or from alternative donors to re- 
ceive prophylactic CSP (starting at the time of transplant) for 6 months or for 24 months after HCT. Patients who did not have clinical manifestations of chronic GVHD on day 80 after HCT were eligible if they previously had experienced acute GVHD or if a skin biopsy showed histologic evidence of (subclinical) chronic GVHD. There were 79 patients randomized to 6 months and 90 to 24 months of CSP. Extensive chronic GVHD developed in 35 of the evaluable 89 patients (39\%) in the 24 months group, and 37 of 73 evaluable patients $(51 \%)$ in the 6 months group, and, thus, the hazard of developing chronic GVHD (0.76, 95\% confidence interval $0.48 \sim 1.21$ ) was not significantly different $(P=0.25)$. Also, there were no significant differences between the two groups in regards to transplantation-related mortality, survival, or disease-free survival. ${ }^{36)}$

Trials of ex vivo T-cell depletion for GVHD prevention using monoclonal antibodies against various $\mathrm{T}$ cell epitopes have generally resulted in a reduced incidence of acute GVHD, but have had a lesser impact on the development of chronic GVHD. ${ }^{37)}$ Those studies include a large randomized trial recently reported by Wagner, et al., which showed that the use of $\mathrm{T}_{10} \mathrm{~B}_{9}$ antibody or soybean lectin agglutination plus CSP did not offer a significant advantage in comparison to CSP/methotrexate prophylaxis, with incidences of chronic GVHD of $24 \%$ and $29 \%$, respectively. ${ }^{38)}$

Nevertheless, there are data to suggest that some T-cell depletion approaches, for example, the use of anti-CD52 antibodies (Campath 1G, 1H and 1M) will reduce the incidence of chronic GVHD. Campath-1M has been used mostly "in the bag", i.e. for in vitro treatment of the donor cell mixture before infusion into the patient, Campath-G mostly in vivo, either as part of the conditioning regimen or after HCT (or both). Kottaridis et al. ${ }^{39)}$ prepared 44 patients with hematologic malignancies with fludarabine and melphalan and added Campath-1H at 20mg/day on days -8 to $-4 ; 36$ patients received PBSC from HLA-identical siblings and 8 received marrow from HLA-matched unrelated donors. Most patients received only CSP for additional GVHD prophylaxis. Among 43 evaluable patients, 42 had sustained engraftment (although only 18 of 31 patients studied were full donor chimeras). At a median follow-up of 9 months, 33 patients were alive in remission (or with stable disease), and only one patient was reported as having developed chronic GVHD.

The use of an anti-CD6 antibody plus complement for in vitro $\mathrm{T}$-cell depletion resulted in an incidence of chronic GVHD of less than 15\% in HLA-identical sibling transplants. ${ }^{40)}$

Recently, there has also been a renewed interest in in vivo T-cell depletion/inactivation, using polyclonal antibodies, particularly rabbit antithymocyte globulin (Thymoglobulin; ATG). Thymoglobulin has been incorporated in various conditioning regimens or has been given shortly after $\mathrm{HCT}^{\left.41^{44}\right)}$ In a small randomized trial in patients given unrelated donor transplants and Thymoglobulin at $15 \mathrm{mg} / \mathrm{kg}$, the incidence of chronic GVHD was $39 \%$ as compared to $62 \%$ in controls $(P=0.04){ }^{41)}$ Seattle's data in patients conditioned with a regimen of targeted busulfan and cyclophosphamide to which Thymoglobulin was added on days $-3,-2$, and -1 for total doses of 4.5 or $6 \mathrm{mg} / \mathrm{kg}$, suggested a reduction in the frequency of GVHD, particularly in its chronic form. ${ }^{45)}$ They noted that in patients transplanted with PBSC from related or unrelated donors the frequency of chronic GVHD was reduced to or below the level observed previously in patients who received marrow as a source of stem cells. ${ }^{45)}$ A similar beneficial effect was observed by Schetelig et al. ${ }^{46)}$ who noted a chronic GVHD incidence of $23 \%$ in 38 patients conditioned with a regimen of fludarabine $\left(180 \mathrm{mg} / \mathrm{m}^{2}\right)+$ busulfan $(8 \mathrm{mg} /$ $\mathrm{kg})$ combined with ATG $(40 \mathrm{mg} / \mathrm{kg})$ compared to $54 \%$ in 45 patients conditioned without the use of ATG $(P=0.02)$. Bacigalupo et al. showed in a long-term follow-up study that patients who had received Thymoglobulin as part of the conditioning regimen had a lower incidence of chronic GVHD and developed fewer pulmonary complications, as determined by superior lung function test during follow-up. ${ }^{42)}$ Similar experience have been reported by our center that the addition of low dose Thymoglobulin $(1.25 \mathrm{mg} / \mathrm{kg} / \mathrm{day}, \mathrm{D}-3, \mathrm{D}-2)$ in combination with TBI and cyclophosphamide in 12 AML patients who received PBSC from unrelated mismatched donor resulted in none of moderate or severe acute GVHD and relapse. ${ }^{47)}$ One report suggests that the 
mechanism by which Thymoglobulin may reduce the frequency of chronic GVHD and induce tolerance is via induction of regulatory $\mathrm{T}$ cells $\left(\mathrm{CD} 4{ }^{+} \mathrm{CD} 25^{\text {high }}\right) .{ }^{48)}$

There is data to suggest that B lymphocytes are also involved in the pathophysiology of chronic GVHD. ${ }^{49)}$ Rituximab is a chimeric murine-human anti-B-cell (CD20) antibody that has been reported to have activity in treating chronic GVHD and other autoimmune diseases. ${ }^{50)}$ A clinical trial to determine if administration of rituximab after HCT can reduce the incidence of chronic GVHD is ongoing in US multi-center study.

\section{IMPLICATIONS OF CHRONIC GVHD}

Chronic GVHD with the associated immunodeficiency, and the effects of glucocorticosteroids and other immunosuppressive treatment used to control GVHD, represent the most frequent late complications after allogeneic HCT.

The risk of non-relapse mortality is higher for patients with chronic GVHD with direct progression from acute GVHD; for patients with platelet counts <100,000/ $\mu \mathrm{L}$; hyperbilirubinemia, extensive skin disease, or multiple organ involvement; and low clinical performance score. $^{51,52)}$ If not treated adequately and in severe cases, chronic GVHD can result in major disability related to keratoconjunctivitis sicca, pulmonary insufficiency due to bronchiolitis obliterans, or restrictive lung disease related to scleroderma or fasciitis, as well as joint contractures, skin ulcers, esophageal and vaginal stenosis, and others. 6,53 )

Most patients require glucocorticosteroids or other agents for at least 2 years from the initial diagnosis of chronic GVHD. ${ }^{51)}$ Approximately $10 \%$ of patients require continued immunosuppressive treatment beyond 5 years from the initial diagnosis of chronic GVHD, and $40 \%$ die or experience a recurrence of their malignancy before chronic GVHD resolves, while $50 \%$ of patients discontinue treatment within 5 years from the initial diagnosis of chronic GVHD. ${ }^{51)}$ Therefore, it is not surprising that corticosteroid and other therapies are major contributors of late complication after allogeneic HCT. Ancillary and supportive care directed at organ-specific control of symptoms or complications resulting from
GVHD and its therapy are central to the management of chronic GVHD. However, most of the recommendations in the current ancillary and supportive care guidelines for patients with chronic GVHD are only based on expert consensus opinion (level III) rather than controlled studies, which highlights the need for more clinical research. ${ }^{54)}$

\section{CONCLUSIONS}

Current strategies for the prevention of chronic GVHD are limited. Prevention of acute GVHD is of central importance. Judicious selection of donor and stem cell source and the use of monoclonal or polyclonal antibodies may result in a lower incidence of chronic GVHD than observed in earlier trials. As prophylactic measures have met with only limited success, long-term clinical monitoring is necessary to identify early signs of chronic GVHD, assess activity versus sequelae caused by GVHD, determine treatment-related toxicity and, most importantly, to prevent late complications. It will be useful to apply the $0 \sim 3$ scoring system proposed by the NIH Consensus Group to assess chronic GVHD manifestation in each organ. ${ }^{6)}$ NIH Consensus proposal will be used for this assessment tool at the time of initial diagnosis, at any time when changes occur during the therapy to control GVHD (e.g., due to an increase in the dose of corticosteroid $\geq 1 \mathrm{mg} / \mathrm{kg}$ every-other-day, substitution of one therapy for another, or additional therapy), and at 6 12 months intervals as long as manifestations of GVHD persist or immunosuppressive treatment continues.

\section{ACKNOWLEDGMENTS}

I thanks Dr. Chang-Ki Min for critical review of the manuscript.

\section{REFERENCES}

1) Duell T, van Lint MT, Ljungman P, et al. Health and functional status of long-term survivors of bone marrow transplantation. EBMT working party on late effects and EULEP Study group on late effects. European group of blood and marrow transplan- 
tation. Ann Intern Med 1997;126:184-92.

2) Deeg HJ, Leisenring W, Storb R, et al. Long-term outcome after marrow transplantation for severe aplastic anemia. Blood 1998;91:3637-45.

3) Glucksberg H, Storb R, Fefer A, et al. Clinical manifestations of graft-versus-host disease in human recipients of marrow from HL-A-matched sibling donors. Transplantation 1974;18:295-304.

4) Mielcarek M, Martin PJ, Leisenring W, et al. Graft-versus-host disease after nonmyeloablative versus conventional hematopoietic stem cell transplantation. Blood 2003;102:756-62.

5) Mielcarek M, Burroughs L, Leisenring $W$, et al. Prognostic relevance of "early-onset" graft-versushost disease following nonmyeloablative hematopoietic cell transplantation. Br J Haematol 2005; 129:381-91

6) Filipovich AH, Weisdorf D, Pavletic S, et al. National Institutes of Health consensus development project on criteria for clinical trials in chronic graft-versus-host disease: I. Diagnosis and staging working group report. Biol Blood Marrow Transplant 2005; 11:945-56.

7) Hess $\mathrm{AD}$, Jones RJ. Autologous graft-versus-host disease. In: Thomas ED, Blume KG, Forman SJ, eds. Hematopoietic cell transplantation. 2nd ed. Boston: Blackwell Science, 1999:342-8.

8) Storb R, Prentice RL, Buckner CD, et al. Graft-versus-host disease and survival in patients with aplastic anemia treated by marrow grafts from HLA-identical siblings. Beneficial effect of a protective environment. N Engl J Med 1983;308:302-7.

9) Cutler C, Giri S, Jeyapalan S, et al. Acute and chronic graft-versus-host disease after allogeneic peripheral-blood stem-cell and bone marrow transplantation: a meta-analysis. J Clin Oncol 2001;19:368591.

10) Zaucha JM, Gooley T, Bensinger WI, et al. CD34 cell dose in granulocyte colony-stimulating factor-mobilized peripheral blood mononuclear cell grafts affects engraftment kinetics and development of extensive chronic graft-versus-host disease after human leukocyte antigen-identical sibling transplantation. Blood 2001;98:3221-7.

11) Wagner JE, Barker JN, Defor TE, et al. Transplantation of unrelated donor umbilical cord blood in 102 patients with malignant and nonmalignant diseases: influence of CD34 cell dose and HLA disparity on treatment-related mortality and survival. Blood 2002;100:1611-8.

12) Sullivan KM, Agura E, Anasetti C, et al. Chronic graft-versus-host disease and other late complications of bone marrow transplantation. Semin Hematol 1991;28:250-9.

13) Remberger M, Aschan J, Lönnqvist B, et al. An ethnic role for chronic, but not acute, graft-versus-host disease after HLA-identical sibling stem cell transplantation. Eur J Haematol 2001;66:50-6.

14) Oh H, Loberiza FR Jr, Zhang MJ, et al. Comparison of graft-versus-host-disease and survival after HLAidentical sibling bone marrow transplantation in ethnic populations. Blood 2005;105:1408-16.

15) Randolph SSB, Gooley TA, Warren EH, et al. Female donors contribute to a selective graft-versus-leukemia effect in male recipients of HLA-matched, related hematopoietic cell transplants. Blood 2004; 103:347-52.

16) Miklos DB, Kim HT, Miller KH, et al. Antibody responses to $\mathrm{H}-\mathrm{Y}$ minor histocompatibility antigens correlate with chronic graft-versus-host disease and disease remission. Blood 2005;105:2973-8.

17) Holmes JA, Whittaker JA. Histocompatibility antigen DR4 is associated with chronic graft-versus-host disease in the south Wales population. Br J Haematol 1989;73:424.

18) Pawelec G, Müller CA, Haen M, Ehninger G. Chronic graft-versus-host disease and HLA-DR4 in the southern German population. Br J Haematol 1990;75:295-6.

19) Kim HJ, Park SJ, Im HW, et al. The association of HLA antigen and GVHD in allogeneic hemopoietic stem cell transplantation with histocompatible sibling donor: a single-center experience in Korea. Int J Hematol 2002;76:267-71.

20) Ho VT, Mirza NQ, Junco Dd D, Okamura T, Przepiorka D. The effect of hematopoietic growth factors on the risk of graft-vs-host disease after allogeneic hematopoietic stem cell transplantation: a metaanalysis. Bone Marrow Transplant 2003;32: 771-5.

21) Jenkins MK, Schwartz RH, Pardoll DM. Effects of cyclosporine A on $\mathrm{T}$ cell development and clonal deletion. Science 1988;241:1655-8.

22) Sakoda Y, Hashimoto D, Asakura S, et al. Donor-derived thymic-dependent $\mathrm{T}$ cells cause chronic graftversus-host disease. Blood 2007;109:1756-64.

23) Zhang C, Todorov I, Zhang Z, et al. Donor CD4+ $\mathrm{T}$ and $\mathrm{B}$ cells in transplants induce chronic graft-versus-host disease with autoimmune manifestations. Blood 2006;107:2993-3001.

24) Kansu E. The pathophysiology of chronic graft-versus-host disease. Int J Hematol 2004;79:209-15.

25) Alpdogan O, Schmaltz C, Muriglan SJ, et al. 
Administration of interleukin-7 after allogeneic bone marrow transplantation improves immune reconstitution without aggravating graft-versus-host disease. Blood 2001;98:2256-65.

26) Alpdogan O, Muriglan SJ, Eng JM, et al. IL-7 enhances peripheral $\mathrm{T}$ cell reconstitution after allogeneic hematopoietic stem cell transplantation. J Clin Invest 2003;112:1095-107.

27) Sinha ML, Fry TJ, Fowler DH, Miller G, Mackall CL. Interleukin 7 worsens graft-versus-host disease. Blood 2002;100:2642-9.

28) Chung B, Dudl E, Toyama A, et al. IL-7 is necessary for induction of experimental graft-versus-host disease (GVHD). Blood 2003;102:149a, \#514.

29) Weinberg K, Blazar BR, Wagner JE, et al. Factors affecting thymic function after allogeneic hematopoietic stem cell transplantation. Blood 2001;97: 1458-66.

30) Seggewiss R, Einsele H. Hematopoietic growth factors including keratinocyte growth factor in allogeneic and autologous stem cell transplantation. Semin Hematol 2007;44:203-11.

31) Lee SJ. New approaches for preventing and treating chronic graft-versus-host disease. Blood 2005;105: 4200-6.

32) Ruggeri L, Capanni M, Urbani E, et al. Effectiveness of donor natural killer cell alloreactivity in mismatched hematopoietic transplants. Science 2002; 295:2097-100.

33) Chan GW, Foss FM, Klein AK, Sprague K, Miller KB. Reduced-intensity transplantation for patients with myelodysplastic syndrome achieves durable remission with less graft-versus-host disease. Biol Blood Marrow Transplant 2003;9:753-9.

34) Chao NJ, Parker PM, Niland JC, et al. Paradoxical effect of thalidomide prophylaxis on chronic graftvs.-host disease. Biol Blood Marrow Transplant 1996;2:86-92.

35) Sokos DR, Berger M, Lazarus HM. Intravenous immunoglobulin: appropriate indications and uses in hematopoietic stem cell transplantation. Biol Blood Marrow Transplant 2002;8:117-30.

36) Kansu E, Gooley T, Flowers ME, et al. Administration of cyclosporine for 24 months compared with 6 months for prevention of chronic graft-versus-host disease: a prospective randomized clinical trial. Blood 2001;98:3868-70.

37) Soiffer RJ, Martin P. T-cell depletion of allogeneic hematopoietic stem cell grafts. In: Atkinson K, Champlin R, Ritz J, et al, eds. Clinical bone marrow and blood stem cell transplantation. 3rd ed. Cam- bridge, UK: Cambridge University Press, 2004:41625.

38) Wagner JE, Thompson JS, Carter SL, Kernan NA. Effect of graft-versus-host disease prophylaxis on 3 -year disease-free survival in recipients of unrelated donor bone marrow (T-cell Depletion Trial): a multi-centre, randomised phase II-III trial. Lancet 2005;366:733-41.

39) Kottaridis PD, Milligan DW, Chopra R, et al. In vivo CAMPATH-1H prevents graft-versus-host disease following nonmyeloablative stem cell transplantation. Blood 2000;96:2419-25.

40) Soiffer RJ, Weller E, Alyea EP, et al. CD6 + donor marrow T-cell depletion as the sole form of graftversus-host disease prophylaxis in patients undergoing allogeneic bone marrow transplant from unrelated donors. J Clin Oncol 2001;19:1152-9.

41) Bacigalupo A, Lamparelli T, Bruzzi P, et al. Antithymocyte globulin for graft-versus-host disease prophylaxis in transplants from unrelated donors: 2 randomized studies from Gruppo Italiano Trapianti Midollo Osseo (GITMO). Blood 2001;98:2942-7.

42) Bacigalupo A, Lamparelli $T$, Barisione $G$, et al. Thymoglobulin prevents chronic graft-versus-host disease, chronic lung dysfunction, and late transplant-related mortality: Long-term follow-up of a randomized trial in patients undergoing unrelated donor transplantation. Biol Blood Marrow Transplant 2006;12:560-5.

43) Remberger M, Svahn BM, Mattsson J, Ringdén O. Dose study of thymoglobulin during conditioning for unrelated donor allogeneic stem-cell transplantation. Transplantation 2004;78:122-7.

44) Remberger M, Svahn BM, Hentschke P, et al. Effect on cytokine release and graft-versus-host disease of different anti-T cell antibodies during conditioning for unrelated haematopoietic stem cell transplantation. Bone Marrow Transplant 1999;24:823-30.

45) Deeg HJ, Storer BE, Boeckh M, et al. Reduced incidence of acute and chronic graft-versus-host disease with the addition of thymoglobulin to a targeted busulfan/cyclophosphamide regimen. Biol Blood Marrow Transplant 2006;12:573-84.

46) Schetelig J, Bornhäuser M, Kiehl M, et al. Reducedintensity conditioning with busulfan and fludarabine with or without antithymocyte globulin in HLA-identical sibling transplantation--a retrospective analysis. Bone Marrow Transplant 2004;33:483-90.

47) Kim HJ, Min WS, Eom KS, et al. Anti-leukemic role of acute GVHD after unrelated haematopoietic stem cell transplantation in intermediate- to high-risk 
acute myelogenous leukemia. Bone Marrow Transplant 2007;40:1069-74.

48) Lopez M, Clarkson MR, Albin M, et al. A novel mechanism of action for anti-thymocyte globulin: induction of CD4+CD25 + Foxp3 + regulatory T cells. J Am Soc Nephrol 2006;17:2844-53.

49) Maury S, Mary JY, Rabian C, et al. Prolonged immune deficiency following allogeneic stem cell transplantation: risk factors and complications in adult patients. Br J Haematol 2001;115:630-41.

50) Cutler C, Miklos D, Kim HT, et al. Rituximab for steroid-refractory chronic graft-versus-host disease. Blood 2006;108:756-62.

51) Stewart BL, Storer B, Storek J, et al. Duration of immunosuppressive treatment for chronic graft-versus-host disease. Blood 2004;104:3501-6.
52) Akpek G, Lee SJ, Flowers ME, et al. Performance of a new clinical grading system for chronic graft-versus-host disease: a multi-center study. Blood 2003; 102:802-9.

53) Lee SJ, Vogelsang G, Flowers ME. Chronic graftversus-host disease. Biol Blood Marrow Transplant 2003;9:215-33.

54) Couriel D, Carpenter PA, Cutler C, et al. Ancillary therapy and supportive care of chronic graft-versus-host disease: National Institutes of Health consensus development project on criteria for clinical trials in chronic graft-versus-host disease: V. Ancillary therapy and supportive care working group report. Biol Blood Marrow Transplant 2006;12: 375-96. 